\title{
RESEARCH PAPER \\ GEO-ELECTRICAL INVESTIGATION FOR SUBSURFACE ELECTRICAL SYSTEM EARTHING AT THE SCHOOL OF MANAGEMENT TECHNOLOGY OF THE FEDERAL UNIVERSITY OF TECHNOLOGY, AKURE, NIGERIA
}

\author{
G. M. Olayanju and F. O. Onaolapo \\ Department of Applied Geophysics, Federal University of Technology, Akure, Nigeria. \\ E-mails:gmolayanju@gmail.com; olawaleonaolapo@yahoo.com \\ Corresponding author: gmolayanju@gmail.com
}

\begin{abstract}
Electrical tomographic imaging and depth sounding techniques were employed in the investigation of the subsoil around the School of Management Technology of the Federal University of Technology, Akure, Nigeria for the purpose of Electrical Earthing. Wenner Dipole-dipole electrical resistivity imaging was conducted along seven traverses in the area with electrode inter spacing ' $a$ ' of $2 m$, with the probing level ' $n$ ' varied from 1 to 5. Twelve Vertical Electrical Soundings were conducted at selected locations based on the results of electrical imaging. The geoelectric sections obtained from inverted sounding data revealed three subsurface geologic layers, which comprise the topsoil, weathered bedrock and the fresh basement rock. The topsoil is composed mainly of clay or sandy clay/ clayey sand or laterite with resistivity values that range from 41 to 739 Ohm-m and thickness ranging from 0.5 to $5.3 \mathrm{~m}$. The weathered bedrock resistivity values ranges from 12 to $363 \mathrm{Ohm}-\mathrm{m}$ with thickness between $1.0 \mathrm{~m}$ and $17.9 \mathrm{~m}$. The underlying fractured/fresh basement rock resistivity varies from 213 to $865 \mathrm{ohm}-\mathrm{m}$. However, the underlying migmatite-gneiss basement rock is relatively shallow. The inverted resistivity sections from the Dipole-dipole and computed ground resistance distribution revealed typical 3- layer earth models revealing majorly five suitable localities with relatively low resistance $(<15$ ohm $)$ with probable depth for the insertion of Earthing materials lying between $1.5 \mathrm{~m}$ and $4 \mathrm{~m}$. In addition, areas characterized by resistance values, between $15 \mathrm{ohm}$ and $25 \mathrm{ohm}$, can be improved upon by adding industrial salts.
\end{abstract}

Keywords: Earthing, Ground resistance, Tomographic Imaging, Wenner Dipole-dipole, Vertical Electrical Sounding

\section{INTRODUCTION}

Earthing of infrastructures usually requires the connection of a conductor of a particular frame of a device (i.e., a metallic lightning device) extending to the general mass of earth with the aim of protecting the infrastructure from damages that might be as a result of excessive current discharge, especially from thunder storms. 


\section{Olayanju and Onaolapo}

Earthing materials play an important role in generation, transmission and distribution for safe and proper operation of any electric installation. These devices form a low-resistance path for the lightning discharge and prevent it from travelling through the infrastructures.

There are a number of good reasons for earthing, but primary among them is to ensure personnel safety. Geophysical applications are essential in many areas of human developmental programmes, especially development of infrastructures, hydrogeology, engineering and foundational studies, environmental studies and planning, among many (Barker, 1990; Herman, 2001; Pfieffer, 2001; Akintorinwa and Adesoji, 2009; Ofomola et al., 2009).

Essentially, the geophysical application of electrical resistivity methods will significantly be suitable in detecting conductive medium through which the earthing installations can be done. The resistance between the earth electrode and "true Earth" is known as the Earth Resistance of an electrode and it will depend on the soil resistivity, the type and size of the electrode and the depth to which it is buried. The resistance of an earth electrode is greatly influenced by the resistivity of the soil in which it is driven and as such, soil resistivity measurements are an important parameter when designing earthing installations. Earthing devices form a low-resistance path for the lightning discharge and prevent it from travelling through the infrastructures; therefore a safe conductive medium is essential for the emplacement of these devices in order to meet electrical safety standards.

Various geophysical methods, for example seismic refraction, ground penetrating radar can help in identifying shallow geologic environment suitable for this purpose.

If the soil resistivity is known or can be measured using the 4-point electrode method, the earthing resistance $R g$ of an earth electrode may be calculated from the earth resistivity $r$ and the electrode geometry used (Markiewicz and Klajn, 2003).

Several authors have demonstrated application of geophysics in ground resistance testing for proper down conductors grounding systems in some journals and handbooks (Beackmann and Schweak, 1976; LEM, 2005; Megger, 2005; Akintorinwa and Adesoji, 2009; AEMC, 2012). Their approaches involve direct measurement of soil resistivity across the area of interest. In this paper in order to identify suitable area for earthing of an academic Building under construction, Vertical Electrical Sounding (VES) and combined Vertical Electrical Sounding and Horizontal Profiling Electrical Techniques were employed.

\section{MATERIALS AND METHODS}

\section{Site description and geology}

The study location is the School of Management Technology site of the Federal University of Technology, Akure campus in Nigeria, which lies within latitudes $7^{\circ} 17^{\prime} \mathrm{N}$ to $7^{\circ} 19^{\prime} \mathrm{N}$ and longitudes $5^{\circ} 07^{\prime} \mathrm{E}$ to $5^{\circ} 09^{\prime} \mathrm{E}$ (Fig. 1). The study area is accessible by a network of roads and foot paths within the Campus. The topography of the area shows a relatively undulating terrain, with surface elevation lying between $375 \mathrm{~m}$ and $377.5 \mathrm{~m}$. The Institution is predominantly underlain by the Migmatite-gneissquartzite complex as shown in Fig. 1, which forms a part of West African Basement Complex.

The migmatite-gneiss-quartzite complex is generally considered as a major group of the West African Basement complex, which has a heterogeneous assemblage comprising migmatites, orthogneisses, paragneisses, and a series of basic and ultrabasic metamorphosed rocks (Rahaman, 1976, 1988). Major rocks outcrops in the area include the Quartzite, Charnockite, Migmatite-gneiss and Granites.

The granitic rocks occur mainly as low-lying outcrops and generally have texture varying from fine grained to medium grained with col- 


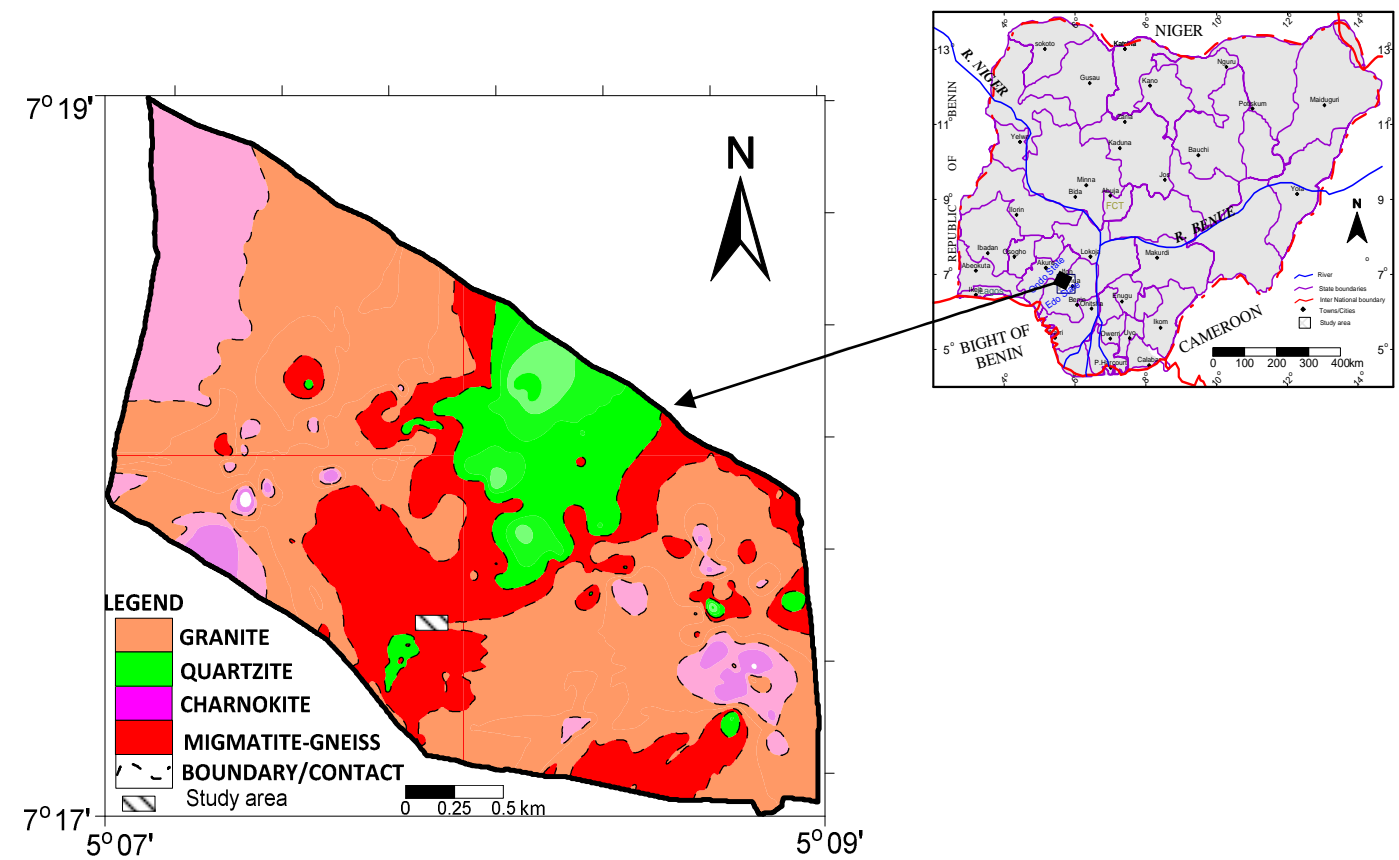

Fig. 1: Geological Map of Federal University of Technology Akure; inset Map of Nigeria (After Olayanju and Ojo, 2015).

our varying from pale brown to greyish. The Charnockites in the area are dark greenish to greenish grey rocks with bluish quartz and greenish feldspar. The greenish colouration is due principally to the presence of hornblende. The Charnockites bear a variable contact relationship with the surrounding rocks, with the transition in contact between the Charnockites and the surrounding granite rocks marked by loss of dark colouration, which is characteristic of the feldspar of the Charnockite. Quartzite occurs mostly as ridges and thin bands (not more than $20-30 \mathrm{~cm}$ in thickness, within the migmatite gneiss) around the area. They occur in the NW-SW direction and are brownish in colour with a medium to coarse grain texture.

\section{Electrical resistivity surveys}

The electrical equipment employed for this paper is the PASI (E2 Digit) Resistivity Meter, which measures and displays the current and potential difference, averaged over a number of cycles. The measured apparent earth resistivity is computed from the output displayed values of the current and voltage averaged over five cycles in order to ensure good quality data. Seven traverses were established, labelled Line 1 to Line 7 in Fig. 2.

Four of these traverses ran south to north, while the other three ran west to east. The geographical coordinates of the data points were established using GERMAN hand held Global Positioning System (GPS). The coordinates were recorded in Universal Transverse Mercator (UTM) coordinate system with the predefined Zone 32 N World Geodetic System 1984 (WGS 84) reference datum.

Electrical imaging of the subsurface along the 


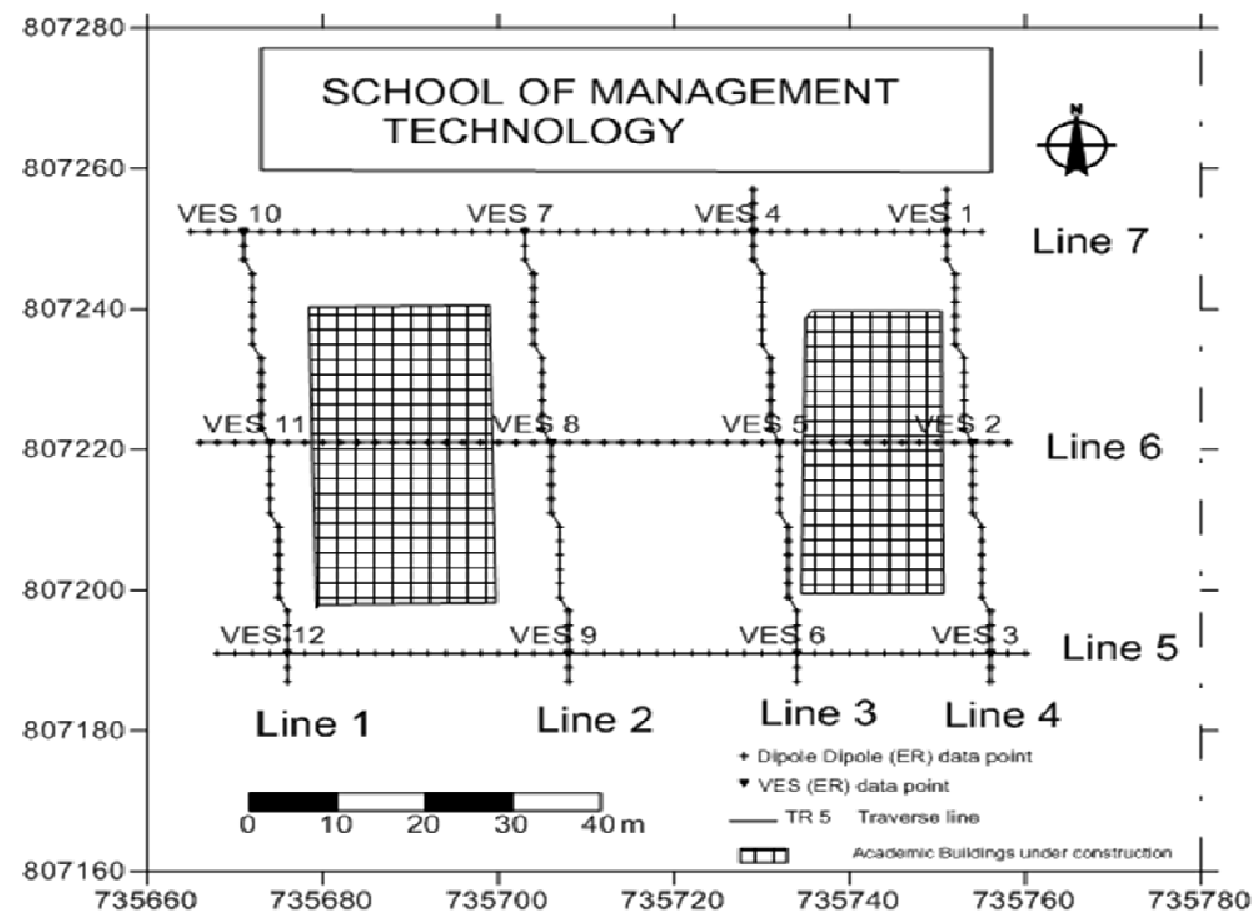

Fig. 2: Field layout of the site of investigation showing electrical resistivity data points and traverse lines.

traverses was made through the display of inverted earth resistivity from the computed earth resistivity using the Wenner Dipole-dipole array type of the combined Vertical Electrical Sounding and Horizontal Profiling technique. The electrode inter spacing ' $a$ ' of $2 \mathrm{~m}$ with maximum probing level ' $n$ ' of 5 was adopted along the seven traverses (Fig. 2). The resistivity inversion of the measured data was conducted using the DIPRO ${ }^{\mathrm{TM}}$ software and inverted resistivity sections (structures) displayed as tomographic images, i.e. pseudo-sections of the shallow subsurface geology of the area.

Twelve Vertical Electrical Sounding (VES) stations were occupied at selected points along the traverses forming a grid network of depth sounding points. The total electrode spread for the vertical electrical soundings was varied from 1 to $40 \mathrm{~m}$. A semi-automated approach to data inversion was adopted in the interpretation of the VES data. The field data were partially curve matched and computed layer resistivity and thickness were used as input for the automatic iteration using WinResist ${ }^{\mathrm{TM}}$ software in order to achieve a best fit to true layer parameters. The results obtained from the inverted field data from the vertical electrical soundings were employed in predicting the stratigraphic sequence under the VES location. Inverted true layer resistivity and thickness values across the traverses were used in generation of geoelectric columnar sections from which the geologic stratigraphic sequence can be correlated within the area.

\section{Computation of earth resistance $\mathrm{Rg}$}

In typical installation of earthing systems, an attempt is made to maximise the surface area contact with the surrounding soil and there are 
series of common methods of earthing. Details of these methods have been documented in Markiewicz and Klajn (2003). However, for this paper the single electrode earthing arrangement was used to model the effective Earth Resistance $(\mathrm{Rg})$ in the study area. There are some formulae for calculating earth resistance for various types and configurations of electrodes as stipulated by the Australian Standard on Lightning protection (AS 1768-1991), which are well documented in details in some publications (ARTC, 2005; Lightning and Surge Technologies, 2014). For a single spike, of diameter (d) and length (L) driven vertically into the soil of resistivity $(\rho)$, the effective Earth resistance $(\mathrm{Rg})$ was computed using the following expression:

$R_{g}=\frac{\rho}{2 \pi L}\left[\ln \left(\frac{8 L}{d}\right)-1\right]$

where: $\rho=$ soil resistivity in ohm-m

$\mathrm{L}=$ Buried length of the electrode in $\mathrm{m}$

$\mathrm{d}=$ diameter of the electrode in $\mathrm{m}$
On the basis of effective soil resistivity values obtained from the inverted Dipole-Dipole resistivity data, information about the distribution of Earth resistance $(\mathrm{Rg})$ within the area was derived using the above expression and the results presented in the form of pseudo sections similar to that of the dipole-dipole electrical imaging.

\section{RESULTS AND DISCUSSION}

\section{Vertical electrical sounding}

The estimated geo-electric parameters from the sounding curves from the study area are shown in Table 1, while the typical sounding curves from the area are displayed in Fig. 3. Qualitative analysis of the Vertical Electrical Sounding data was based on the observed frequency plot (Fig. 4).

Three curve types were delineated, with the $\mathrm{H}-$ type dominant in the area having maximum rate of occurrence $(50 \%)$, followed by the A - type (42\% rate of occurrence) and the $\mathrm{KH}$ - type having $8 \%$ rate of occurrence. The H-type is typical of pronounced weathering effect charac-

Table 1: Table showing the VES interpretation results from the measured field data

\begin{tabular}{llll}
\hline & \multicolumn{3}{c}{ Geoelectric Parameters } \\
Thickness of the & Depth to the & Layer \\
Geoelectric Layer: & Geoelectric Interface: & Resistivity: \\
\hline
\end{tabular}

\begin{tabular}{|c|c|c|c|c|c|}
\hline $\mathbf{S} / \mathbf{N}$ & $\begin{array}{l}\text { VES } \\
\text { Station }\end{array}$ & $\begin{array}{l}\text { Curve } \\
\text { Types }\end{array}$ & $\begin{array}{l}\mathbf{h}_{1} / \mathbf{h}_{2} / \mathbf{h}_{3} / \ldots / \mathbf{h}_{\mathrm{n}-1} \\
(\mathrm{~m})\end{array}$ & $\begin{array}{l}d_{1} / d_{2} / d_{3} / \ldots / d_{n-1} \\
(m)\end{array}$ & $\begin{array}{l}\rho_{1} / \rho_{2} / \rho_{3} / \ldots \ldots / \rho_{n} \\
(\text { ohm-m) }\end{array}$ \\
\hline 1 & 3 & A & $1.4 / 1.0$ & $1.4 / 2.4$ & $41 / 160 / 3280$ \\
\hline 2 & 4 & A & $2.1 / 3.1$ & $2.1 / 5.2$ & $104 / 171 / 467$ \\
\hline 3 & 6 & $\mathrm{~A}$ & $5.3 / 3.3$ & $5.3 / 8.6$ & $76 / 333 / 3036$ \\
\hline 4 & 8 & $\mathrm{~A}$ & $0.9 / 17.9$ & $0.9 / 18.8$ & $54 / 75 / 490$ \\
\hline 5 & 9 & A & $1.8 / 7.1$ & $1.8 / 8.9$ & $41 / 61 / 3124$ \\
\hline 6 & 1 & $\mathrm{H}$ & $0.5 / 2.2$ & $0.5 \overline{/ 2} .7$ & $133 / 53 / 2376$ \\
\hline 7 & 2 & $\mathrm{H}$ & $3.5 / 6.8$ & $3.5 / 10.3$ & $739 / 72 / 865$ \\
\hline 8 & 7 & $\mathrm{H}$ & $0.5 / 10.6$ & $0.5 / 11.1$ & $240 / 58 / 535$ \\
\hline 9 & 10 & $\mathrm{H}$ & $3.3 / 6.9$ & $3.3 / 10.2$ & $128 / 62 / 2549$ \\
\hline 10 & 11 & $\mathrm{H}$ & $1.3 / 4.2$ & $1.3 / 5.5$ & $141 / 37 / 4840$ \\
\hline 11 & 12 & $\mathrm{~A}$ & $3.4 / 6.5$ & $3.4 / 9.9$ & $42 / 120 / 363$ \\
\hline 12 & 5 & $\mathrm{KH}$ & $2.2 / 2.4 / 4.0$ & $2.2 / 4.6 / 8.6$ & $114 / 203 / 56 / 213$ \\
\hline
\end{tabular}



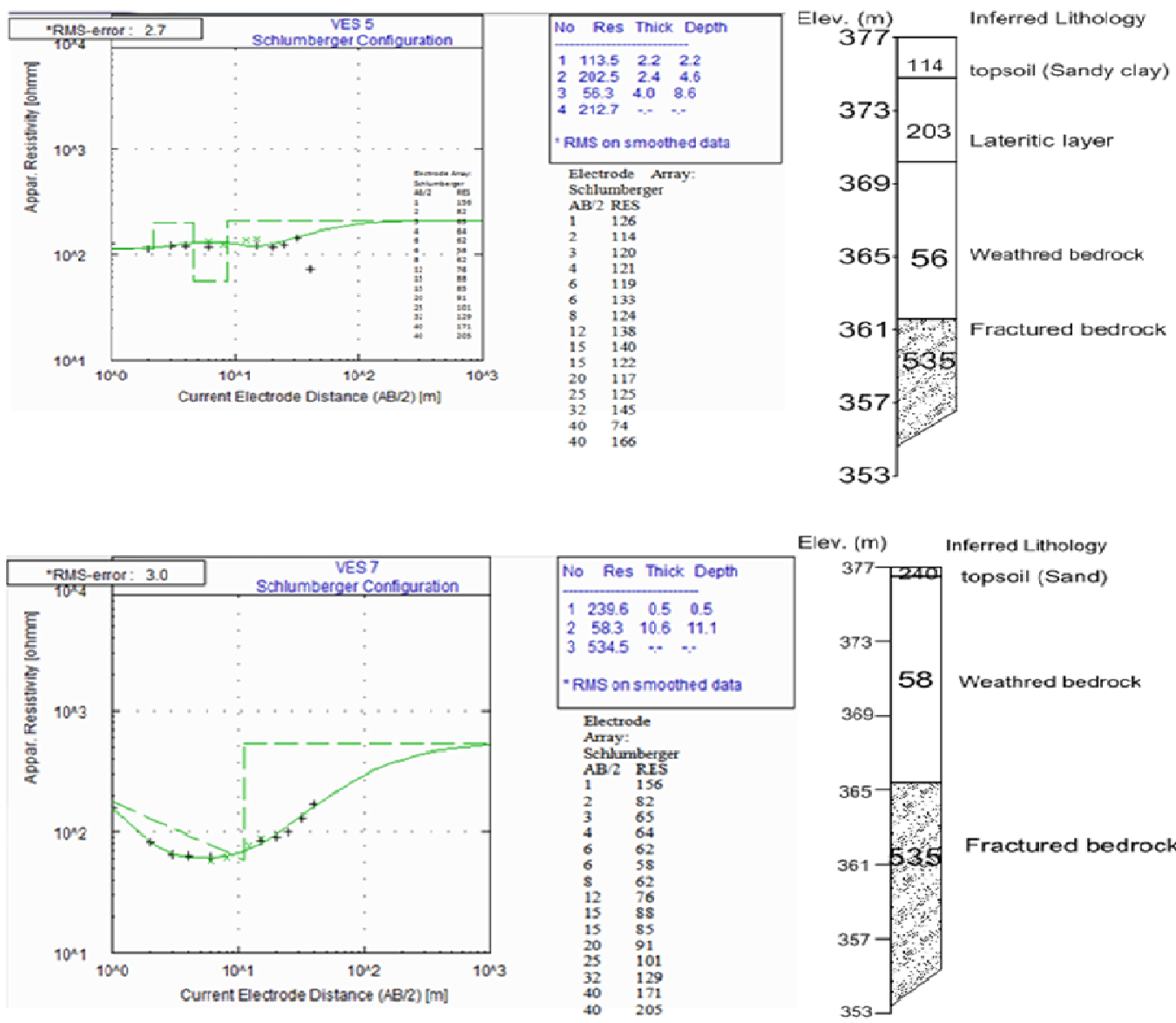

Elev. (m) Inferred Lithology
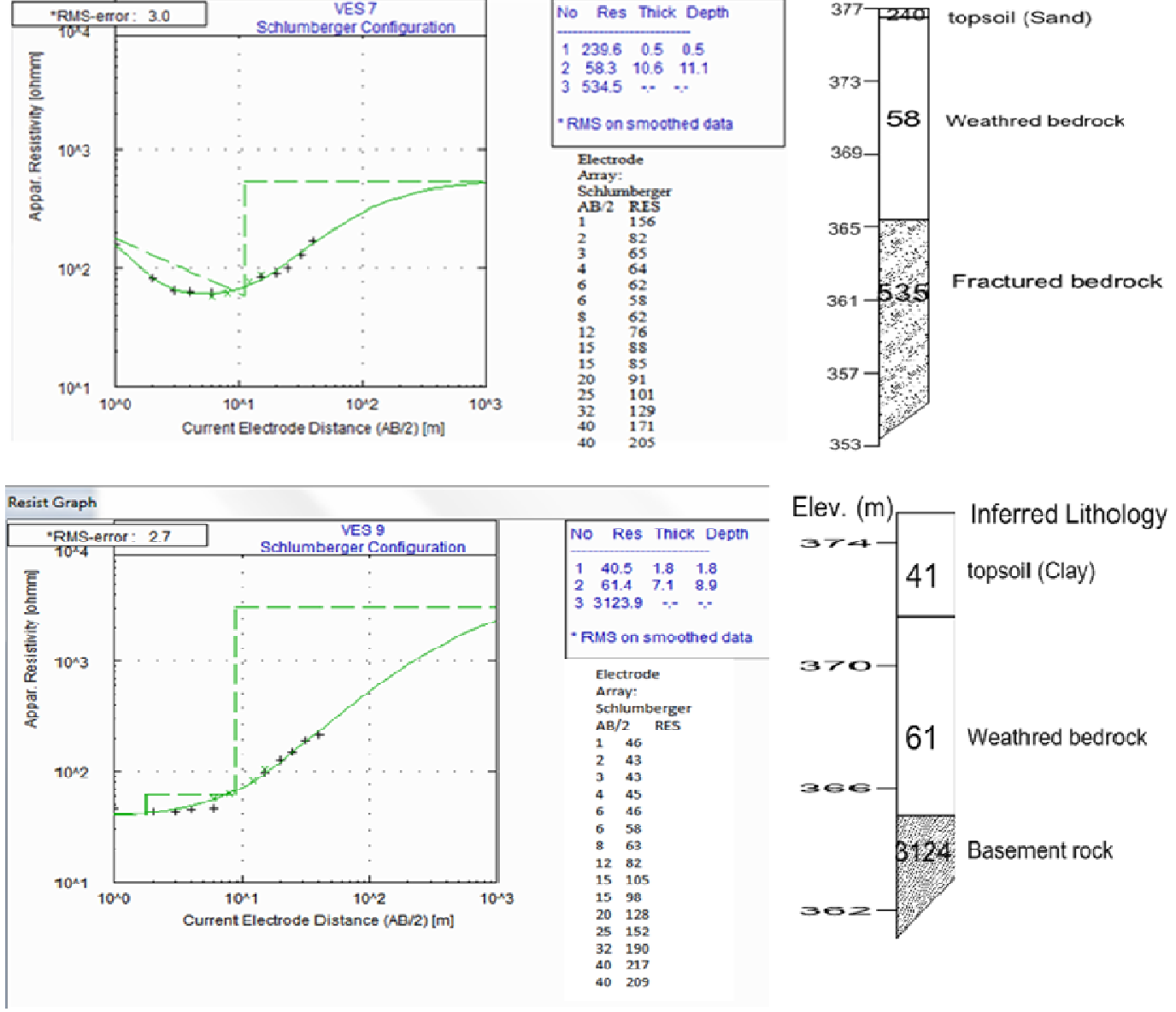

Fig. 3: Typical vertical electrical sounding curves obtained from data inversion 


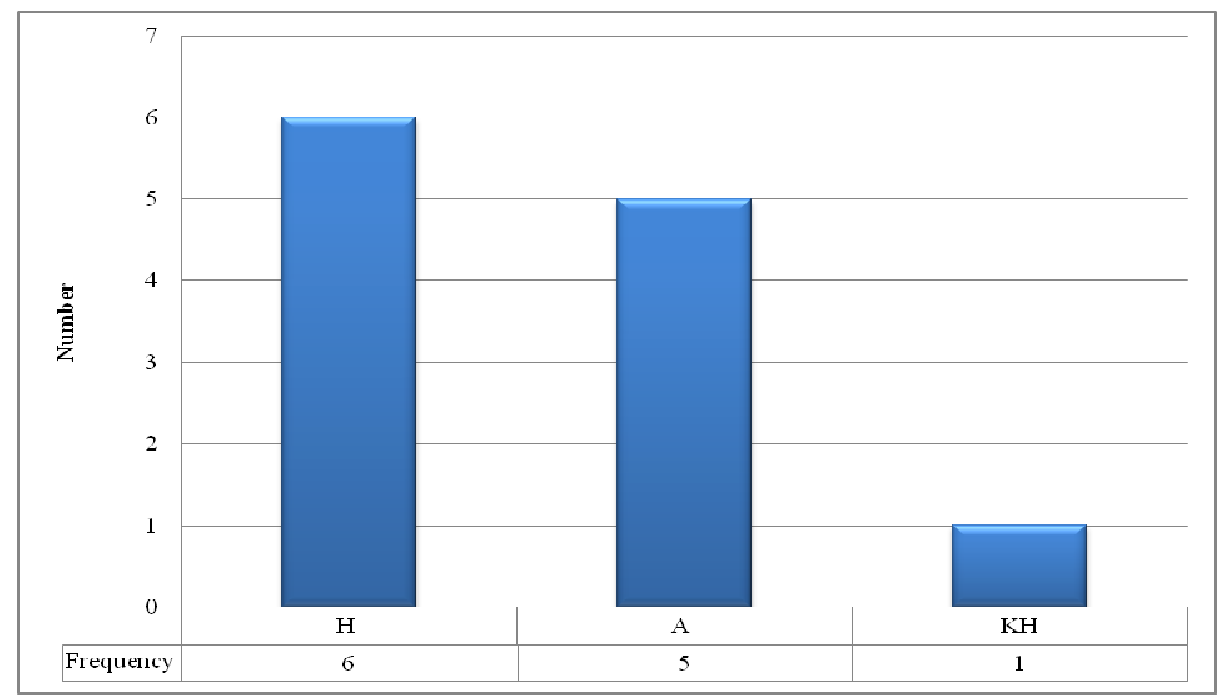

Fig. 4: The frequency distribution chart of the curve types in the study area

terized by low to intermediately high resistive clayey to lateritic topsoil (41 to $739 \mathrm{ohm}-\mathrm{m}$ ); saturated weathered layer ( 37 to $61 \mathrm{ohm}-\mathrm{m}$ ); and fractured/fresh basement (535 to $4840 \mathrm{ohm}$ -m). The A - type curves are diagnostic of shallow bedrock in the area, with progressive increase in resistivity from a low resistive (41 to 104 ohm-m) clayey topsoil to saturated and highly weathered layer (12 to $333 \mathrm{ohm}-\mathrm{m}$ ) overlying the fractured/fresh basement rock with resistivity value ranging from 326 to 3280 ohm- $\mathrm{m}$. The KH curve type indicates the presence of clayey topsoil with resistivity values of $114 \mathrm{ohm}$, which is underlain by clayey sand layer with resistivity value of $203 \mathrm{ohm}-\mathrm{m}$. Beneath this intermediate layer lies a saturated and highly weathered layer having resistivity value of $56 \mathrm{ohm}-\mathrm{m}$ underlying by highly fractured bedrock ( $213 \mathrm{ohm}-\mathrm{m})$.

In most cases the topsoil is relatively thin $(2.1 \pm$ 1.4) $\mathrm{m}$, while average overburden is $8.5 \pm 4.4$ $\mathrm{m}$. The relatively low bedrock resistivity values observed at VES 2, 4, 5, 7, 8 and 12 locations are diagnostic of development of secondary porosity, which might arise from fracture- ing of the bedrock and are more significant in groundwater development.

However, some shallow zones of low resistivity value along the stratigraphic sections characterized by these curves could be relevant in earthing scheme, especially at VES 3, 9 and 12 locations with probable depth less than $5 \mathrm{~m}$.

\section{Dipole-Dipole electrical imaging}

Characteristic earth images (pseudo-sections) of the immediate shallow parts of the subsurface in the area are shown in Figs. 5 and 6. The geoelectric stratigraphic columns are superimposed on the inverted pseudo sections (resistivity structures) from the dipole-dipole electrical imaging. This allows the correlation of the geoelectric sections with the 2D resistivity structures in order to identify zones of conductive medium for earthing in the area. Since it is required that earth electrodes must ideally penetrate into the moisture level below the ground level, emphasis is laid on the immediate shallow layers for the purpose of the electrical earthing systems. 

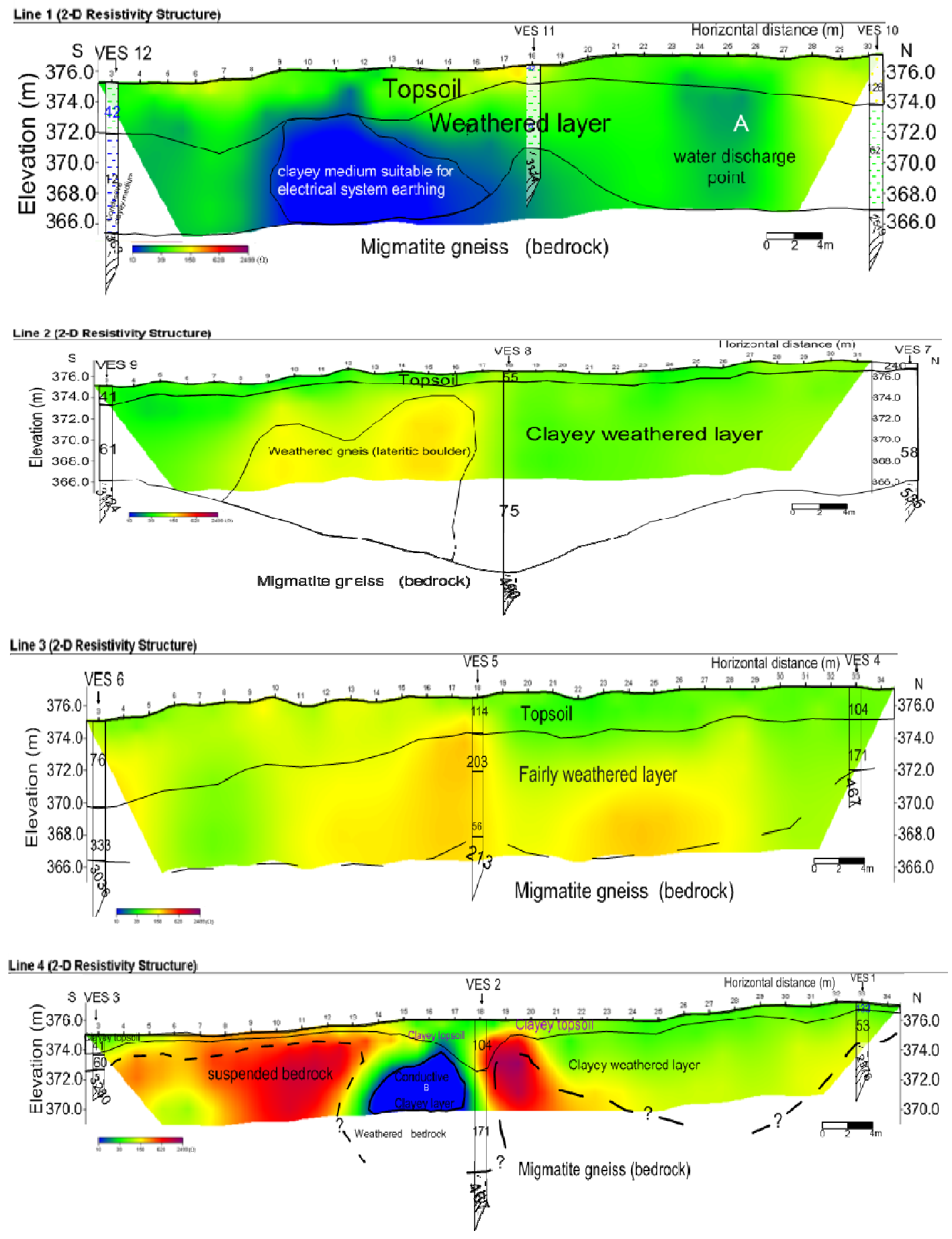

Fig. 5: Electrical structures along S-N orientation in the study area 
Investigation of subsoil for the purpose of electrical earthing... 18
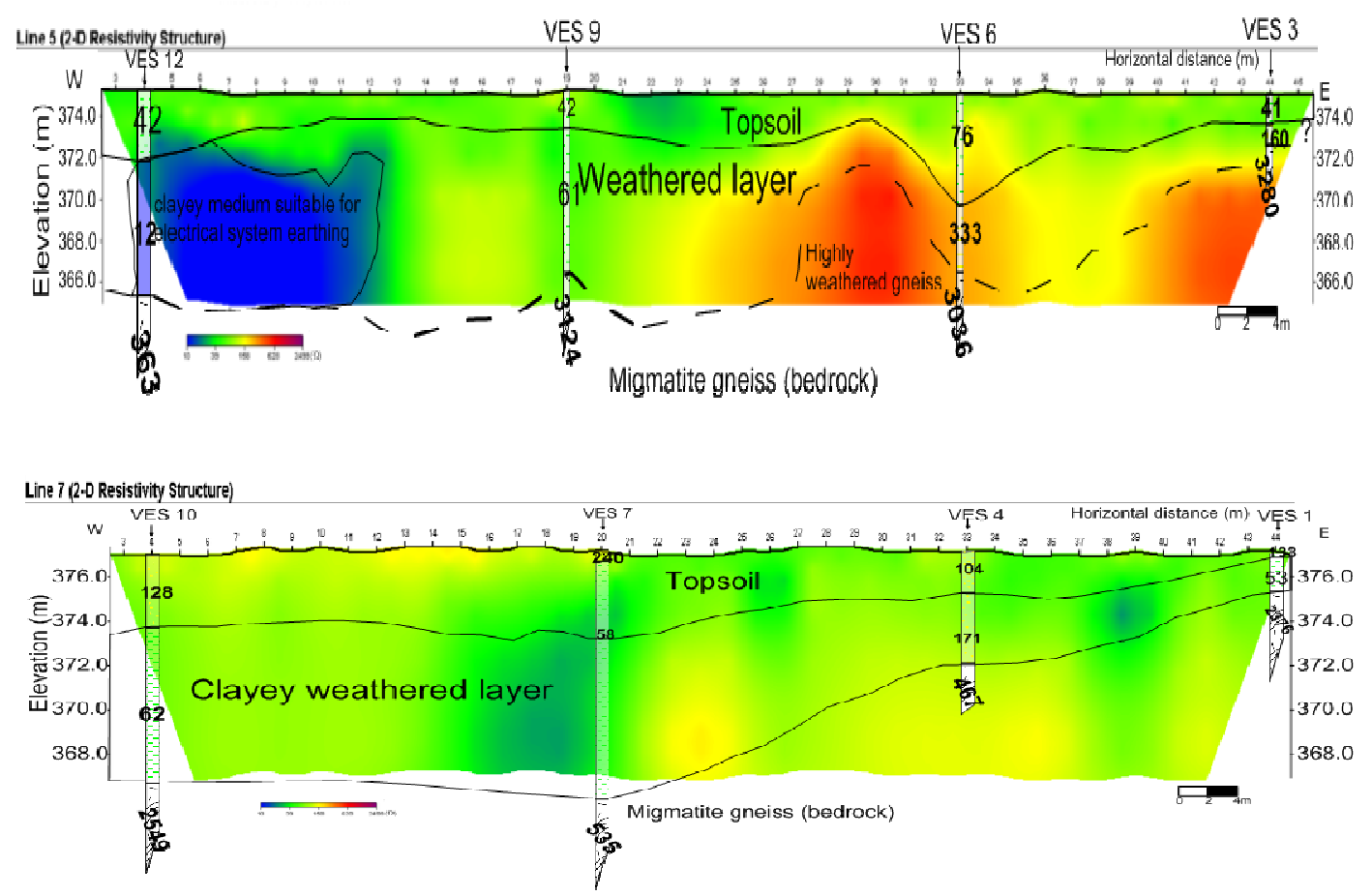

Fig. 6: Electrical structures along W-E orientation in the study area

The inversion of the Dipole-Dipole electrical data obtained along traverses labelled Line 1 4 in the S-N, and Line $5-7$ in the W-E direction are presented as images of the Earth models of the inferred resistivity structures in the area with the aid of DIPRO $^{\mathrm{TM}}$ tomographic software. The areas identified to be suitable for the electrical earthing systems are marked out on the tomographic displays of the resistivity structures in the area.

Toning effect of the tomographic displays of the inverted resistivity structures depict characteristic resistivity (consequently conductivity) of the intermediate medium encountered in the study area. In conjunction with the VES results obtained in the area, the south-western edge of the study area was recognized to be characterized by resistivity value less than $25 \mathrm{Ohm}-\mathrm{m}$.
The suitable conductive zones for electrical earthing systems are located beneath VES 12 (around stations $3-5$ ) and low resistivity zone (i.e. conductive zone) extending from 16 to 30 $\mathrm{m}$ (station $9-17$ ) along traverse 1 (Line 1) along S-N direction.

Along traverse 5 (Line 5), the observed conductive zone lies between the start of the traverse and $22 \mathrm{~m}$ (station $1-12$ ) away from the beginning of the traverse in the W-E direction. Also, along traverse 1 (Line -1 ), the conductive zone labelled A along corresponds to a water discharge point (bleeding point), while the conductive zone labelled $\mathrm{B}$ along traverse 4 (Line 4) is also characterized by resistivity value less than $25 \mathrm{ohm}-\mathrm{m}$, which signify the possible zones of interest for the earthing purpose. However, the earthing system is likely to fail at these locations due to relatively high resistivity 


\section{Olayanju and Onaolapo}

values of surrounding soil in the area.

\section{Distribution of earth resistance $\mathbf{R g}$}

A typical result of the computed $\mathrm{Rg}$ obtained along Line 1, with effective depth of investigation of $2 \mathrm{~m}$ is shown in Table 2, which shows that the earth resistance reduces with reduction in the length or diameter of the earthing rod.
From the results of electrical tomography, the distributions of the computed effective ground resistance in the area are displayed as pseudosection (resistance structures) in Figs 7 and 8. The displays show variation in Earth resistance computed from the inverted earth resistivity along the profiles based on a $3 \mathrm{~m}$ length earthing rod with a diameter of $2.5 \mathrm{~mm}$.

Table 2: Extract of computed ground resistance from effective resistivity values along Line-1

\begin{tabular}{|c|c|c|c|c|c|}
\hline $\begin{array}{l}\text { Ground distance } \\
\text { (m) }\end{array}$ & $\begin{array}{l}\text { Elevation } \\
(\mathbf{m})\end{array}$ & $\begin{array}{l}\text { Effective Resistivity } \\
\text { (Ohm-m) }\end{array}$ & $\begin{array}{l}\text { Eg }(L=2 \mathrm{~m}, \\
\mathrm{D}=2.5 \mathrm{~mm})\end{array}$ & $\begin{array}{l}\mathrm{Eg}(\mathrm{L}=3 \mathrm{~m}, \\
\mathrm{D}=2.5 \mathrm{~mm})\end{array}$ & $\begin{array}{l}\mathrm{Eg}(\mathrm{L}=4 \mathrm{~m}, \\
\mathrm{D}=2.5 \mathrm{~mm})\end{array}$ \\
\hline 0 & 374.95 & 37.40 & 23.10 & 16.21 & 12.58 \\
\hline 0.5 & 374.949 & 38.05 & 23.51 & 16.49 & 12.80 \\
\hline 1 & 374.949 & 38.58 & 23.84 & 16.72 & 12.98 \\
\hline 1.5 & 374.949 & 38.18 & 23.59 & 16.55 & 12.85 \\
\hline 2 & 374.95 & 37.56 & 23.21 & 16.28 & 12.64 \\
\hline 2.5 & 374.95 & 37.00 & 22.86 & 16.03 & 12.45 \\
\hline 3 & 374.95 & 36.95 & 22.83 & 16.01 & 12.43 \\
\hline 3.5 & 374.95 & 38.85 & 24.01 & 16.84 & 13.07 \\
\hline 4 & 374.95 & 41.18 & 25.45 & 17.85 & 13.86 \\
\hline 4.5 & 374.949 & 43.31 & 26.76 & 18.77 & 14.57 \\
\hline 5 & 374.948 & 45.56 & 28.15 & 19.75 & 15.33 \\
\hline 5.5 & 374.948 & 49.66 & 30.68 & 21.52 & 16.71 \\
\hline 6 & 374.95 & 55.49 & 34.28 & 24.05 & 18.67 \\
\hline 6.5 & 374.953 & 63.95 & 39.51 & 27.72 & 21.52 \\
\hline 7 & 374.955 & 73.82 & 45.61 & 31.99 & 24.84 \\
\hline 7.5 & 374.955 & 75.89 & 46.89 & 32.89 & 25.54 \\
\hline 8 & 374.95 & 80.04 & 49.45 & 34.69 & 26.93 \\
\hline 8.5 & 374.938 & 90.40 & 55.85 & 39.18 & 30.42 \\
\hline 9 & 374.929 & 103.34 & 63.85 & 44.79 & 34.77 \\
\hline 9.5 & 374.929 & 104.50 & 64.57 & 45.29 & 35.16 \\
\hline 10 & 374.95 & 106.68 & 65.91 & 46.24 & 35.90 \\
\hline 10.5 & 374.995 & 115.61 & 71.43 & 50.11 & 38.90 \\
\hline 11 & 375.053 & 125.55 & 77.57 & 54.41 & 42.25 \\
\hline 11.5 & 375.11 & 117.19 & 72.40 & 50.79 & 39.43 \\
\hline 12 & 375.15 & 108.08 & 66.78 & 46.84 & 36.37 \\
\hline 12.5 & 375.164 & 103.93 & 64.21 & 45.04 & 34.97 \\
\hline 13 & 375.169 & 101.20 & 62.53 & 43.86 & 34.05 \\
\hline 13.5 & 375.19 & 89.47 & 55.28 & 38.78 & 30.11 \\
\hline 14 & 375.25 & 84.66 & 52.31 & 36.69 & 28.49 \\
\hline 14.5 & 375.362 & 79.67 & 49.22 & 34.53 & 26.81 \\
\hline 15 & 375.505 & 75.69 & 46.76 & 32.80 & 25.47 \\
\hline 15.5 & 375.645 & 69.65 & 43.03 & 30.19 & 23.44 \\
\hline 16 & 375.75 & 65.45 & 40.44 & 28.37 & 22.02 \\
\hline 16.5 & 375.796 & 60.83 & 37.58 & 26.36 & 20.47 \\
\hline 17 & 375.797 & 56.81 & 35.10 & 24.62 & 19.12 \\
\hline 17.5 & 375.774 & 54.17 & 33.47 & 23.48 & 18.23 \\
\hline 18 & 375.75 & 51.58 & 31.87 & 22.35 & 17.36 \\
\hline 18.5 & 375.741 & 48.73 & 30.10 & 21.12 & 16.40 \\
\hline 19 & 375.743 & 46.04 & 28.44 & 19.95 & 15.49 \\
\hline
\end{tabular}


Investigation of subsoil for the purpose of electrical earthing... 20
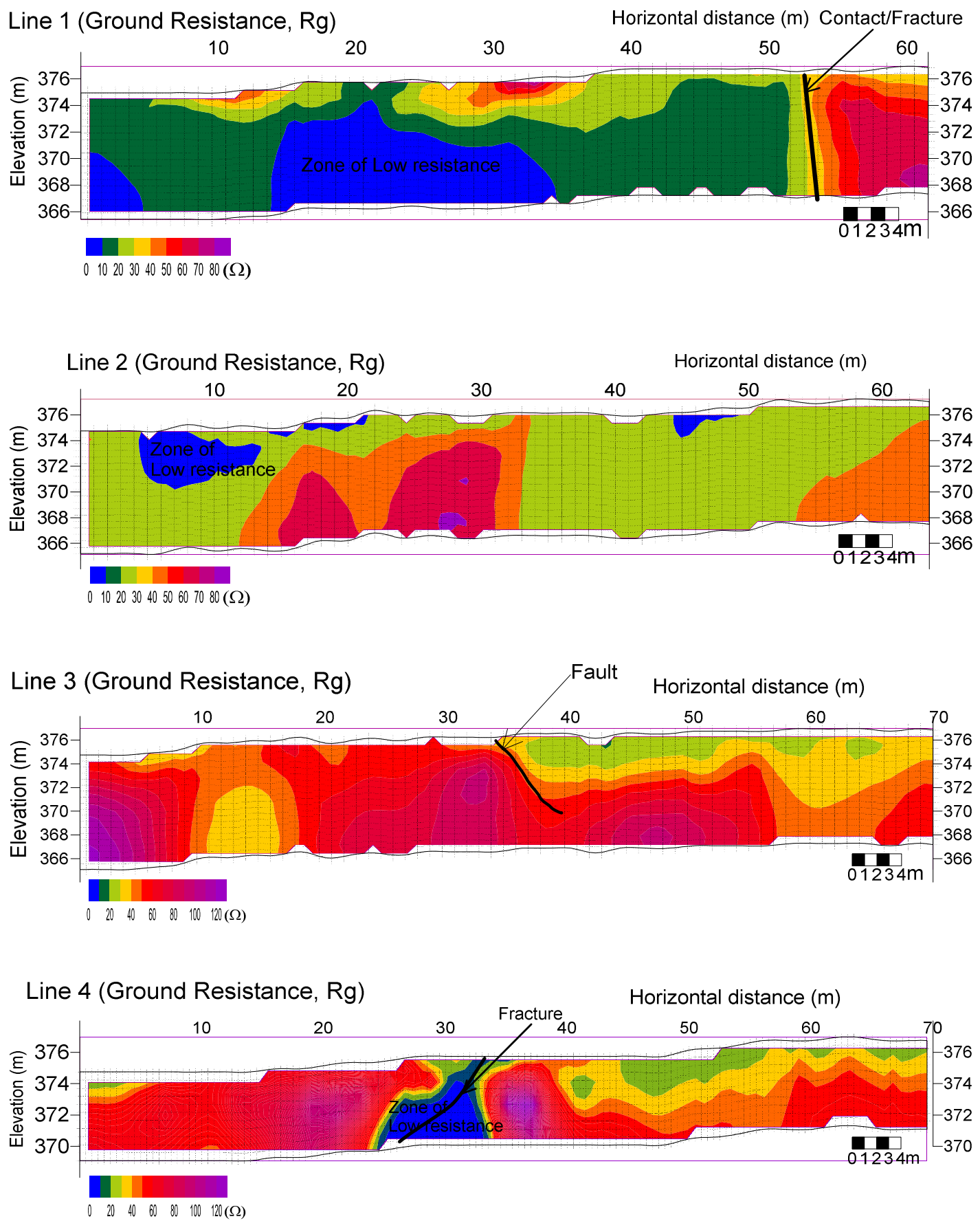

Fig. 7: Ground resistance structures along S-N orientation in the study area 
21 Olayanju and Onaolapo
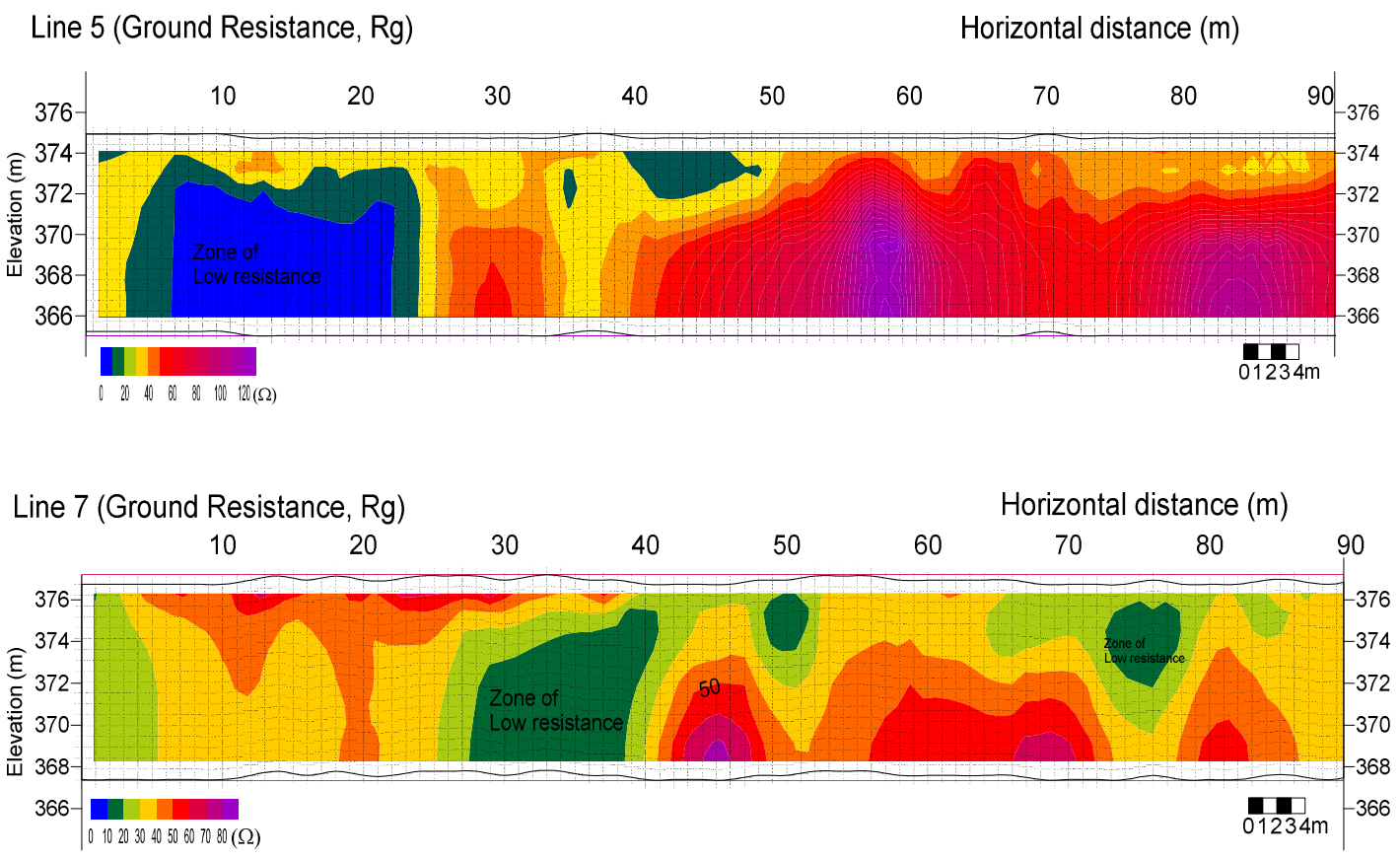

Fig. 8: Ground resistance structures along W-E orientation in the study area

In conformity with the resistivity structures' displays, the areas of low earth resistance are shown with blue tones, while intermediate resistance values are shown in yellowish to reddish tones and areas of high resistance are depicted by magenta.

Since it is not practicable to have an area with zero resistance, the upper limit of $10 \mathrm{ohm}$ was set as a matter of choice by the authors for effective and safe earthing system in the area and not as a rule.

In Fig. 7, a low resistant section suitable for earthing system is observed along Line 1 , at a depth of about $4 \mathrm{~m}$ and close to the central part of the profile. This section corresponds to a clayey portion identified on Fig. 5. From the diagram, a contact between a highly weathered rock and more resistive bedrock is delineated to the northward end of the profile.
In the second pane, suitable section of the profile along line 2 is delineated close to the southern end, while distinct toning effects reflecting clear colour separations suggest textural difference from two different rock types with varying degrees of weathering along the profile. On the third pane, it is observed that though there is no effective area of low resistance that might be exploited for earthing purpose, however, the toning effect revealed subsurface geology indicating shallow bedrock with features such as fault and bedrock depression. The fourth pane showing ground resistance along line 4 revealed a low resistance section with a linear feature identified as fracture.

In Fig. 8, the first pane shows the ground resistance structure along Line 5 with characteristic toning effect revealing low resistance section in the western part of the profile and textural difference indicating varying degrees of weather- 
ing of underlying rock. The second pane in Fig. 8 however shows that the profile along Line 7 which revealed that the immediate subsurface materials might not be favourable for good earthing system.

\section{CONCLUSION}

The geophysical surveys conducted around the Management Technology School of the Federal University of Technology, Akure have revealed suitable subsurface geology for electrical earthing of building at the identified sections of the area. The results obtained from the Vertical electrical Sounding data and displays from dipole-dipole tomographic and ground resistance distributions within the area of study revealed the subsurface geology indicating with relatively shallow bedrock. In addition, the topsoil is geo-technically competent for the low -rising building in the area. Geo-electric sequence delineated through the use of Vertical Electrical Sounding technique revealed a subsurface stratigraphic sequence comprising of the topsoil, weathered bedrock and the fractured/fresh basement rocks, with overburden thickness lying between $2.4 \mathrm{~m}$ and $18.8 \mathrm{~m}$. The topsoil is composed mainly of the sand/clayey sand/ sandy clay and laterite with resistivity values that range from 41 to 739 Ohm-m and the thickness ranging from 0.5 to $5.93 \mathrm{~m}$. The weathered basement, which is a weathered product of migmatite/gneiss, has resistivity values that range from 12 to $333 \mathrm{Ohm}-\mathrm{m}$ and thickness of 1.0 to $17.9 \mathrm{~m}$. The geo-electric structures identified in the area indicate the presence of a potential fractured zone.

From the results of the electrical imaging, the south-western part of the study area is more appropriate for electrical earthing of the infrastructures in the area. In addition areas of intermediate low resistance values, (15 - $25 \mathrm{ohm})$ can be improved upon in order to have the earthen rods inserted into some parts of the study area, while the rods must be placed at a depth ranging from 0.5 to $3.5 \mathrm{~m}$ around VES 9 and VES 12 location respectively for effective results. Although, there is a possibility of chal- lenges in establishing a suitable location for groundwater abstraction, however, most areas identified with low bedrock resistivity (213 $865 \mathrm{ohm}-\mathrm{m})$ are likely to harbour groundwater due to the development of secondary porosity arising from fracturing of the underlying migmatite gneiss.

\section{REFERENCES}

AEMC, (2012). Understanding Ground Resistance Testing. AEMC Instruments, USA. Accessed from http://www.aemc.com, in September, 2014.

Akintorinwa, O. J., and Adesoji, J. J. (2009). Application of geophysical and geotechnical investigations in engineering site investigation at a site in the south-eastern part of Nigeria. International Journal of Physical Science, 4 (8): $443-454$.

ARTC (2005). Lightning and Surge Protection Requirements. Australian Rail Track Corporation. Accessed from http:// extranet.artc.com.au/docs/eng/signal/ procedures/construction/ SCP04.pdf, in September, 2014).

Barker, R. D. (1990). Investigation of Groundwater Salinity by Geophysical Methods, in Ward, S.H. Ed., Geotechnical and Environmental Geophysics 02: Society of Exploration Geophysicist, 201-211.

Beackmann, W. V. and Schweak, W. (1976). Handbook on cathodic protection. Theory and Practice of electrochemical corrosion protection techniques. Portucullis press survey, London.

Herman, R. (2001). An Introduction to Electrical Resistivity in Geophysics. American Association of Physics Teachers, 69 (9): 943 952.

LEM, (2005). Electrical grounding techniques, A 99415 E Publication, Ground Resistance Principles, Testing, Techniques and Applica- 
tions. Accessed from http://www.lem.com, in September, 2014.

Lightning and Surge Technologies (2014). Earthing Fundamentals. Accessed from http://www.lightningman.com.au/ Earthing.pdf, in September, 2014.

Markiewicz, H. and Klajn, A. (2003). Earthing Systems - Fundamentals of Calculation and Design. 'Earthing and EMC Power Quality Application Guide', Wroclaw University of Technology.

Megger, (2005). Getting down to Earth, A practical guide to earth resistance testing. Accessed from http://www.megger.com in September, 2014.

Ofomola, M. O., Adiat, K. A. N., Olayanju, G. M. and Ako, B. D. (2009). Integrated Geophysical Methods for Post Foundation Stud- ies, Obanla Staff Quarters of the Federal University of Technology, Akure, Nigeria. The Pacific Journal of Science and Technology, $10(2): 333-359$.

Olayanju, G. M. and Ojo, A. O. (2015). Magnetic Characterisation of Rocks Underlying FUTA Campus, South-Western Nigeria. In Press.

Pfieffer, J. C. (2001). Principles of electrical grounding. Pfieffer Engineering Co. Inc., Louisville.

Rahaman, M. A. (1976). Review of the Basement geology of South Western Nigeria. (In) Geology of Nigeria, C.A. Kogbe (ed): 41-56.

Rahaman, M. A. (1988). Recent Advances in the study of the Basement Complex of Nigeria. (In) Precambrian Geeology of Nigeria, second edition: 11-45. 